\title{
Die Bene parișim bei Daniel: 11, 14.
}

\section{Von D. A. Schlatter.}

Unter den Konsequenzen der These, dafs unsre sämmtlichen Erzähler der makkabäischen Geschichten: 1 Mk., 2 Mk. und die von Josephus in den Ant. mit der Paraphrase von 1 Mk. verbundne Nebenquelle, die ich Eupolemus nenne ${ }^{1}$ ), aus der grolsen, fünf Bücher umfassenden Arbeit Jasons ihren Stoff geschöpft haben, ist eine der interessantesten die, dafs es dadurch wahrscheinlich wird, dafs Menelaos und seine Brüder Simon und Lysimachus Tobiaden gewesen sind, so dals das hohepriesterliche Haus durch die Steuerpächter übermocht und vernichtet worden ist.

Die Beweisführung stand bisher so: Die Nebenquelle des Jos. (Eup.) ist schlecht, wie ihre falschen Briefe augenscheinlich machen, und hat dennoch Stücke, die nur aus einem stoffreichen und wohlunterrichteten Erzähler stammen können. Sogar vom grolsen Antiochus erhalten wir noch echte Dokumente, A. 12, 3. 3. 4, und die Geschichte der Tobiaden hat zwar durch mehrfache Ueberarbeitung gelitten, ist aber auch so noch sehr konkret und illustrirt die $\mathrm{Zu}-$ stände Jerusalems unmittelbar vor dem Eintritt der Katastrophe im hohepriesterlichen Haus vorzüglich, A. 12, 4.

1) Diels darum, weil die in diesen Einlagen vorliegende Chronologie uns ausdrücklich als Eupolemus gehörend durch Klemens Strom. 1, 21. P. 404 überliefert ist. Uebrigens liegt am Namen wenig. Wer meine Schlüsse für gewagt hält, wird Eup. als willkürliche Bezeichnung des von Jos. benützten zweiten Erzählers verstehn. Näheres Studien u. Kritiken 1891, 633.

Zeitschrift f. d. alttest. Wiss. Jahrg. 14. 1894. 
Dals Eup. nicht aus 1. oder 2. Mk. schöpft, lehrt der Augenschein. Dagegen hat er mehrere Kongruenzen mit Jason:

1) Auch 2. Mk. 4, 11 erwähnt zu Gunsten Jerusalems erlassne Dekrete des Königs, worunter der grolse Antiochus verstanden sein wird. Solche Dekrete stehn bei Eup.

2) Der Tobiade Hyrkan, sein Reichthum und seine Abwesenheit von Jerusalem, werden 2 Mk. 3, 11 als bekannt erwähnt, so dals Jason hiervon gesprochen haben muls. Die Geschichte der Tobiaden steht bei Eup.

3) Die Hohepriesterreihe Onia, Jason, Menelaos steht bei Eup. ${ }^{1}$ ) wie bei Jason, A. 12, 5, 1.

4) Von Judas Verhandlungen mit Rom gab Jason Bericht, 2. Mk. 4, 11. Eup. hat den Bundesvertrag überarbeitet, A. 12, 10, 6. 417-419.

5) Jason hat gesagt, dafs die Samariter um die Umwandlung ihres Tempels in einen Zeustempel baten, 2. Mk. 6, 2. Eup. hat eine Petition der Samariter an Epiphanes zu diesem Zweck verffalst, A. 12, 5, 5, $258 \mathrm{ff}$.

6) Die Hinrichtung des Menelaos in Beroia stand bei Jason, vgl. 2. Mk. 13, 4, und bei Eup. A. 12, 9, 7. 385.

7) Alkimus wird bei Jason schon durch Lysias nach dem Tod des Menelaos Hohepriester, vgl. 2. Mk. ${ }_{-}^{r-14}$, 7 , ebenso bei Eup. A. 12, 9, 7. 385.

8) In der Chronologie stimmt Jasions Ansatz: Zweiter Zug des Lysias gegen Jerusalem 149 Sel. 2. Mk. 13, 1 mit dem Ansatz des Eup.: 414 seit dem .Exil bis zur Hinrichtung des Menelaos und 420 bis zum 5ten Jahr des Demetrius. Denn Demetrius hat 1. Mk. 7,1 als erstes Jahr

1) Allerdings mit der offenbaren, vielleicht aber von "Jos. iherrührenden Verderbnils; dals Menelaos zum Sohn Onias wird. Es war eben den spätern völlig unglaublich, dals ein nicht priesterliches Geschlecht: während mehrern Jahren den Hohenpriester ersetzt haben sollte. 
151 Sel. Die von Eupolemus gerechneten 6 Jahre sind das zweite Jahr des Eupator und die 5 des Demetrius. Die andre Angabe: 408 bis zur Verheerung des Tempels läfst sich aus Jason nicht belegen, weil 2. Mk. im ersten Theil keine Jahrzahl erhalten hat. Es widerspricht ihr aber in Jasons Berichten nichts, da sie die Anwesenheit. des Epiphanes in Jerusalem auf 143 Sel. bringt.

Diese Kongruenzen zwischen Eup. und Jason scheinen mir so eng und so bedeutsam, dals es als wahrscheinlich bezeichnet werden darf, dals Eup. aus Jason schöpft. Gesetzt, dieser Schlufs sei richtig, dann stand die Tobiadengeschichte vor 2. Mk. 3, und dies bestätigt sich nicht nur dadurch, dafs Hyrkan ohne weiteres in der Erzählung erscheint, sondern auch dadurch, dafs sein Todfeind Simon, der die Syrer gegen seine Gelder hetzt, und dessen Brüder, Menelaos und Lysimachus, ohne jede weitere Beschreibung auftreten, als wären sie uns längst bekannt. Ging die Tobiadengeschichte voran und sind Simon und Menelaos die älteren legitimen Söhne Josephs, die Hyrkan aus Jerusalem vertrieben haben, dann wulste der Leser des unverstümmelten Jason allerdings, warum Simon auch durch die Heiligkeit des Tempels sich nicht davon abhalten liels, die Gelder Hyrkans in die Hand der Syrer zu spielen, und warum Menelaos ein so mächtiger Mann gewesen ist, dals er die Hohepriester zu verdrängen und sich selbst, ohne Aaronide zu sein, als Hohepriester zu behaupten vermochte.

Eine konfuse Erinnerung an das Eingreifen der Tobiaden in die makkabäischen Wirren steht nun zweimal in verschiedner Form bei Jos., bj. 1, 1, 1 und A. 12, 5, 1. 239. Selbstverständlich gewänne aber die ganze Argumentation beträchtlich an Sicherheit, wenn auch Daniel die Tobiaden als die Urheber der Katastrophe bezeichnete. Ich lege den Kollegen die Frage vor: ob dies nicht Dan. 11, 14 geschieht. ובעתים ההם רבים יעמדו על מלך הנגב 
ובני פריצי עמך ינשאו להעמיד חוון ונכשלו. Wir stehn zwischen dem ersten und zweiten Feldzug des grofsen Antiochus gegen Egypten. Es folgt sofort die Eroberung der עיר מבצרות, Sidons, und darauf die Verlobung der Kleopatra mit Ptolemäus Epiphanes.

Deutlich ist, dals die Worte von einer emporkommenden jüdischen Gruppe oder Familie reden, weiter, dafs Daniel dieselbe verabscheut, und endlich, dafs die hier gemeinten Leute in enger Beziehung zu den makkabäischen Wirren stehen müssen. Denn ihr Aufkommen leitet die Erfüllung des »Gesichts « ein, was unmöglich nur auf diesen einzigen Vers bezogen werden kann, sondern auf die ganze Weissagung von der Noth unter Antiochus Epiphanes gehen muls.

Bevan $^{1}$ ) hat auf jede Erklärung verzichtet. Er nimmt

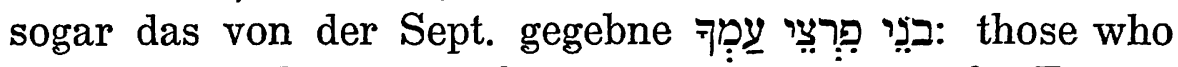
build up the breaches of thy people, wieder auf. - Er vermuthet schlielslich einen gewaltsamen Versuch zur Restauration Israels.

Neben der ältern Auslegung scheint mir Bevans Verzicht nicht unbegründet. Hieronymus zog die Flucht des jüngern Onia nach Egypten bei, eine chronologische Unmöglichkeit. Auch die Erinnerung an die Hilfe, welche die Juden dem syrischen Heer gegen die in der Akra sich haltenden egyptischen Truppen leisteten (Hitzig), trägt zur Erklärung des Verses nichts aus. Nachdem Jerusalem durch die Syrer genommen war, war diese Politik unmittelbar gegeben. Das unerträglichste waren zwei fremde Besatzungen in der Stadt, von denen die eine die Akra, die andre den Tempel und die Stadt hielt, und die nun mit einander Krieg führten. Das handgreifliche Interesse der Judenschaft ging damals dahin, die Egypter aus der Akra herauszudrängen. Es lälst sich darum nicht erläu-

I) a short commentary on the book of Daniel, 1892 Cambridge. 
tern, warum die mit den Syrern gegen die Egypter Kämpfenden בני פריצים sein sollen, und noch weniger läfst sich sagen, warum das »Gesicht « durch diesen nichts weiter nach sich ziehenden Umstand zur Erfüllung gebracht werden soll.

Sind die jüdischen בני פריצים die Tobiaden, so erläutert sich zunächst ohne Schwierigkeit, warum ihr Emporkommen die Erfüllung des Gesichts zur Folge hat. Denn dafs die Tobiaden unter dem grolsen Antiochus zur Macht gelangten, hat Menelaos in den Stand gesetzt, Jason zu verdrängen, Onia ermorden zu lassen, und für sich selbst das Hohepriesterthum zu kaufen, woraus in unaufhaltsamer Verkettung der Dinge die ganze Katastrophe unter Epiphanes erwachsen ist.

Weiter erläutert sich בני פריצים. Bevan scheint mir mit Recht gesagt zu haben, es stehe nicht einfach für פריצים, so wenig für צריקים gesagt werde. בני ist nur dann nicht mülsig, wenn es sich um ein Geschlecht handelt, das seine gewaltsam erworbne und behauptete Stellung auf mehr als eine Generation vererbte. Ueber den Grofsvater Tobia wissen wir nichts, als dals das Geschlecht bleibend nach ihm benannt wurde:

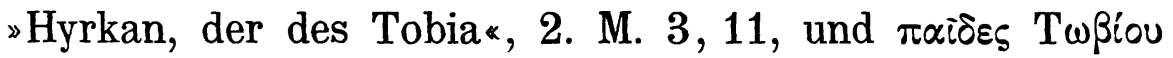
bei Jos. Wann die Familie grofs geworden ist, sagt uns das Fragment nicht. Joseph erscheint gleich von Anfang an als Mann der Schwester Onias, gehört also, noch ehe er die Steuern von ganz Palästina in Alexandrien pachtete, bereits $\mathrm{zu}$ den Magnaten Jerusalems. So versammelt er auch das Volk in den Tempel, und erscheint als der berufne Vertreter desselben, nachdem Onia sich nicht mit der egyptischen Regierung einlassen will. Diese Machtstellung hat er sodann auf seine Söhne vererbt.

פריצים palst vortrefflich als Name der Tobiaden. Joseph zog an der Spitze seiner von Egypten ihm geliehenen Soldtruppen im Lande herum und machte sogar Städte 
wie Askalon und Skythopolis durch Grausamkeit mürbe. Seine Söhne führten mit einander offnen Krieg, und Hyrkan schlug sich von seinem Tyrus aus auch mit den Arabern. Dals für Simon und Menelaos פריץ das rechte Wort ist, versteht sich ohnehin von selbst.

Aber auch נכשלו macht keine Schwierigkeit.' Es lag kein Segen auf dem Geschlecht. Ehe Hyrkan aus Jerusalem vertrieben wurde, tötete er zwei seiner Brüder; er selbst endete, als er den Widerstand gegen die Syrer aufgeben mulste, durch Selbstmord. An Iysimachus übte das Volk summarische Justiz. Wie Simon endete, wissen wir nicht. Menelaos aber gilt Daniel vollends als ein gestrauchelter, obwohl er, als Daniel schrieb, noch am Leben war.

Die uns bei Jos. erhaltne Geschichte setzt einige Jahre später ein, als die Angabe Daniels. Sie beginnt in dem Moment, wo Palästina kKleopatra zur Mitgift gegeben wurde und dadurch in finanzielle Abhängigkeit von Alexandrien $\mathrm{kam}^{1}$ ). Zugleich erhalten wir aber die Zahlen: Joseph sei 22 Jahre Steuerpächter gewesen, und Hyrkan habe nach seinem Tode 7 Jahre auf Tyrus residirt, A. 12, 4, 10. 224 und 234. Sein Untergang wird dem Regierungsantritt des Antiochus Epiphanes gleichzeitig gesetzt. Ich habe schon 1891 darauf hingewiesen, dals nach diesen Ziffern die Steuerpacht des Joseph mit dem Regierungsantritt des unmündigen Ptolemäus Epiphanes gleichzeitig wird. So fügen sich die beiden Stellen auch chronologisch auf's beste zusammen. Das Aufkommen der Tobiaden fällt in die Zeit, wo Antiochus nach dem Tode des Euergetes auf Palästina losfuhr. Joseph erwirbt von den Syrern die Steuerpacht in Jüdäa. Hierauf werden durch die Schenkung des Antiochus die Steuer- und Rechtsverhältnisse in Palästina zweifelhaft. Man verlangt von Alexandrien aus die Steuern. Onia trägt Bedenken; Joseph dagegen benützt klug die neue Regelung dieser Verhältnisse und erwirbt 